\title{
MAORI DEAF IDENTITY
}

\author{
Kirsten Smiler
}

\begin{abstract}
This paper outlines some of the research findings of my MA Thesis, which is entitled Maori Deaf: Perceptions of cultural and linguistic identity of Maori members of the New Zealand Deaf community. I asked research participants to describe the nature of their life experiences within Maori and Deaf worlds. These narratives unveiled some of the typical issues facing Maori Deaf within their day-to-day life, upbringing, language development, relationships and identification with these two worlds. Although a part of Te Ao Maori and the Deaf World, participants described feelings of being 'on the fringes', which they attributed to minimal cross-cultural and linguistic understanding between people from the respective worlds. Some responded to this by creating a cultural and linguistic space that was uniquely Maori Deaf. I describe some of these cross-cultural misunderstandings and introduce a model to help with understanding how participants articulated their identity as multifaceted and responsive.
\end{abstract}

WHAKAPAPA

Ko Okahuatiu te maunga

Ko Waikakariki te awa

Ko Repongare te roto

Ko te Whanau a Kai te hapu

He uri o te Turanga nui a Kiwa me Te Whanau o Ngati Turi ahau, ko Kirsten Smiler toku ingoa

The practice of outlining whakapapa (genealogical history) or shared social connections is well established within Deaf and Maori communities. Considering the nature of this article, I begin with my whakapapa (connections) to both the Deaf World ${ }^{1}$ and Te Ao Maori (the Maori-world). My connection to these two groups stems from my parents. My mother is Pakeha Deaf (she has 
a brother who is also Deaf), and my father is hearing Maori. From a young age I was socialised into the Deaf World and Te Ao Maori simultaneously. New Zealand Sign Language (NZSL), taught to me by my mother in the home, was my first language. This was shortly followed by English, which was used by both my maternal extended family and paternal whanau. My introduction to Te Reo Maori came a little later. Aside from a smattering of Te Reo Maori used within my father's whanau, there was very little opportunity to learn Te Reo Maori within a natural language context. Instead, my 'formal' introduction to Te Reo Maori began during the 1980's when I was placed in a bilingual 'whanau unit' at intermediate school, the first of its kind in our community. ${ }^{2}$ The need to switch between cultural contexts was common, and my siblings and I were expected to navigate Te Ao Maori, the Deaf World and mainstream New Zealand society from a young age.

Although not perfect, my siblings and I managed to be flexible, to adapt and to accept - something that many adults we knew struggled to do. As I became older I noted common cross-cultural misunderstandings between Maori and Deaf communities. Common examples included Maori hearing people making crude comments about my mother, calling her 'deaf and dumb' and talking about 'how lucky she was to have children who could hear for her'. Aware that I was eavesdropping into adult conversations and in fear of hurting my mother's feelings, I used to say nothing. While the Deaf community was used to such prejudice, it was also no stranger to inflicting prejudice. Although 'tight-knit' and including Maori, Pacific and Asian people, it wasn't always a multi-cultural community in practice. It seemed to me that it wasn't very 'fashionable' to be a non-Pakeha in the Deaf community. This manifested in the use of what would now be deemed 'politically incorrect' NZSL signs ${ }^{3}$ and other discrete social nuances. For example, I can still recollect a conversation I had with a Pakeha Deaf adult, who commented on the high number of Maori and 'Islanders' (Pacific Island people) who lived in the area I grew up in - this was apparently distasteful. Again I was unsure of what an appropriate response was, so I smiled and said nothing. Other misconstrued ideas of Maori people and culture from within the Deaf community stemmed from what they 'saw'. Watching the 'All Blacks' doing the haka was something that I knew stirred some Pakeha Deaf people into fits of laughter, followed by exaggerated facials that were aimed to mimic the pukana [facial expressions] used within haka.

Cultural ignorance in these communities meant there was a role for my siblings and I - cultural brokers. These activities included acting as a communicator between Deaf and hearing people (regardless of ethnicity), and ex- 
plaining cultural perspectives or 'ways of doing things'. From the perspective of a young child this was frustrating and confusing, because what seemed 'common sense' to me was completely foreign to some adults. While working within a broker capacity, I saw Maori Deaf people sitting on the boundaries of both these worlds. Within Te Ao Maori they participated as observers with no or limited access to language. In Deaf circles they lived with little knowledge or opportunity to express themselves as Maori. Over the years I have noted gradual 'improvements' in cross-cultural awareness between Maori and Deaf, Deaf and hearing, Pakeha and Maori. For Deaf people, increased access to NZSL interpreters has been instrumental to their participation in this process. Not only do interpreters provide a service for the impartial interpretation of language, they also increase the likelihood of dialogue between communities, allowing new rhetoric to flow into the minds of Maori and Deaf people. Nevertheless, I still see Maori Deaf people sitting on the fringes.

These childhood experiences prompted me to formulate the research objective for my MA thesis, namely to investigate and describe the characteristics of Maori Deaf socialisation experiences in terms of the Deaf World and Te Ao Maori. I sought to provide a model for understanding the multiple identities of Maori Deaf people. This paper outlines some of the key research findings from this study.

THE DEAF-WAY AND TIKANGA MAORI: INFORMING THE METHODOLOGY

When embarking on the data collection processes for this study I was struck by a lack of 'formal guidance' in the literature, leading me to begin my investigation by reviewing Maori and Deaf methodologies separately. This initial review revealed strong similarities in terms of the 'concerns' held by both Deaf and Maori communities as separate entities. These concerns centred on the way in which Deaf and Maori communities have historically been the 'objects' of research. In this type of research their knowledge has been interpreted within the framework of the cultural and linguistic majority. In response, Maori communities called for 'Kaupapa Maori' research - research done by and for Maori within Maori cultural frameworks and asserting Maori priorities (Smith 1999). Significantly, Deaf researchers identified a similar objective - a non-deficit approach to research that accepts Deaf people in terms of their cultural and linguistic identity as Deaf as opposed to being a disability minority (Baker-Shenk and Kyle 1990; Ladd 2003). This literature also challenges the ability of outsiders to interpret the knowledge within Deaf communities without tainting it with ethnocentric lenses and promotes the view that Deaf research should aim to reflect the realities and priorities of Deaf people. 
In light of the obvious similarities, I began to collect the data for this study in line with the Deaf-Way (Deaf cultural norms) and Tikanga Maori (Maori principles). In many ways these cultural practises and expectations overlapped. Mindful of this I aimed to be responsive to participants' dual memberships to Te Ao Maori and the Deaf World. The data collection process for this study began with employing whakawhanaungatanga [the principle of connectedness]. Several key Maori Deaf community leaders and organisations such as 'Te Komiti o Ruamoko Marae" were contacted with the aim to consult and seek tautoko [support]. Gaining tautoko was seen as a particularly important process, which ensured 'unrestricted' access to the community and its resources. This process also placed me as an agent for fulfilling research objectives as deemed appropriate by the community.

Although I had a fair idea that the over-arching research questions for this study would be compatible with the communities' priorities, I began the consultation process by 'checking' the research questions. Luckily, the focus of the study was readily accepted within the community, which led to the next stage - finding participants. It was decided that a purposeful sampling technique would be the most effective way to capture the diversity of life experiences amongst Maori Deaf people. A list of potential research participants was formulated using personal networks, my supervisor's networks and networks of 'Te Komiti o Ruamoko Marae'. Factors affecting the criteria for selection included:

- A balance of males and females;

- A range of ages;

- Variation in urban/rural origin;

- A range of levels of perceived Maori Deaf consciousness and involvement;

- A range of levels of perceived Te Ao Maori consciousness and involvement; and

- Variation in school backgrounds, such as Deaf school, Deaf unit or mainstream school.

These criteria ensured variation and a breadth of responses as well as commonalities in life experience that could be represented.

The consultation process was especially useful in terms of accessing participants. Contacted using Maori Deaf networks, all participants exhibited an eagerness to 'tell their story'. Interviews were conducted face-to-face in NZSL, and recorded on videotape. Approximately one to two hours in length, a semistructured interview schedule was used to prompt informants to speak about 
their life experiences within the Deaf World and Te Ao Maori. These interviews were later translated into written English and analysed thematically according to the research questions and themes arising from the interviews.

\section{RESEARCH FINDINGS}

The data collected for this study unveiled a myriad of issues facing Maori Deaf in terms of the nature of their day to day lives, upbringing, language development, relationships and identification with both the Deaf World and Te Ao Maori. Two themes discussed at length in my research included:

-What was it like being Maori Deaf in a Deaf World? and

-What was it like being Maori Deaf in a Maori hearing World?

This paper outlines some key issues surrounding these themes and introduces a model to help make sense of the complex identities described by participants.

\section{BEING MAORI DEAF IN THE DEAF WORLD}

American academics Baker and Cokely (1980:56) proposed that Deaf people primarily access the Deaf World and Deaf communities through four avenues: audiological, social, linguistic and political. The model they used to represent this access is presented in the following figure.

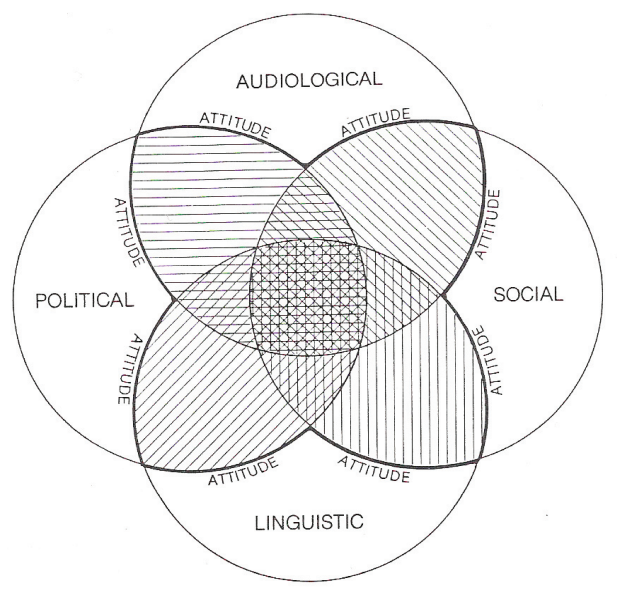

Figure 1. Avenues to membership in the Deaf-community (Reproduced from Baker and Cokely 1980:56). 
This model proposes that there are four overlapping areas in which Deaf people can access the cultural entity of the Deaf World. The heavily shaded central area indicates those who are able to access the Deaf World via all four avenues. In this sense they are considered more rooted in their identity and cultural orientation to the Deaf World. These people are often referred to in the academic world as the 'core Deaf community'. In NZSL they are described by the term that is loosely translated as 'Strong Deaf'. The area highlighted by the 'attitude barrier' is an important cultural border and illustrates a perimeter of shared cultural assumptions and attitudes. Ascribing to these key assumptions is an important part of formulating a Deaf identity. Significantly, there are often individuals who access a Deaf community via two or three Deaf avenues, while maintaining the shared assumptions toward Deaf identity. These people commonly include children of Deaf parents, sign language interpreters and friends and spouses of Deaf people. Nevertheless, it is the 'core Deaf community' which acts as the mainstay of the Deaf culture, language and identity. The following section describes some of the common complexities concerning Deaf people's ability to access these avenues.

\section{The Audiological Avenue}

The most obvious avenue of access to the Deaf community is the audiological avenue and includes those that experience significant hearing loss. For most people the physical experience of deafness shapes a worldview that differs from hearing people. Being deaf requires a person to rely heavily on other senses such as sight and touch; communication must almost always be visual. This visual orientation to the world and to communication means that many Deaf people tend to feel more at home with others who are like them. Consequently, for most Deaf people, being 'Deaf' is not so much about being audiologically impaired as about realising that they are different to hearing people. Meeting other Deaf children or Deaf people usually cements this identity and results in the individual beginning to see themselves as culturally Deaf.

The age at which the onset of deafness occurs is also an important factor in the way in which people respond to the audiological avenue. Those who become deaf prior to the development of spoken language or in the early stages of language development usually adjust readily to a visual communication and language. Those whose onset occurs in adulthood usually prefer to keep with spoken language and regard themselves as hearing-impaired. These people are not typically considered a part of the Deaf community because they tend not to ascribe to the shared attitudes of the Deaf community. Nevertheless, in many ways, the physical sensation of 'deafness' is not one that ever leaves 
a culturally Deaf person; rather it becomes a less-centralised part of the person's identity.

\section{The Social and Linguistic Avenues}

Socialisation into Deaf communities is complicated, and not all deaf people are automatically members of a Deaf community, because they experience deafness or hearing-impairment differently. Indicators of membership include knowledge of Deaf culture and participation within a local Deaf community. Participation in a Deaf community can only be navigated through the use of a sign language such as New Zealand Sign Language (NZSL), which is a vehicle for socialisation. Some people have fewer opportunities to mix with Deaf children or are dismissive of their Deaf identity because of external pressure to conform (to behave like hearing people) and thus view themselves as hearing-impaired. Although these people develop many skills to function in the hearing world, their participation is often marginalised by the barriers that Deaf people typically face in the hearing world, such as limited access to information and participation. In addition, these people often struggle when they enter the adult Deaf community - where these issues are not usually a problem - because they are not familiar with sign language and Deaf culture. Many Deaf people have this experience of living in a 'no man's land', lacking confidence in their identity

\section{The Political Avenue}

The ability to participate in the social and linguistic avenues also affects access to the Deaf community via the political avenue, or a Deaf person's ability to influence a Deaf community on a local or national level. Without social and linguistic experience it is difficult if not impossible for a Deaf person to participate in the Deaf community at this level. Despite this, some advances in information technology such as e-mail and text messaging have opened new forums in which discussion within the Deaf community can occur. It is possible that these ways of communicating may alter the types of political participation Deaf people can have within the community.

\section{Applying the Model}

Maori Deaf people interviewed for this study all found that accessing the Deaf World involved a complex and sometimes arduous journey along one or more of these avenues. Accepting sign language as a natural language despite the stigma attached to it by wider hearing society was difficult, as was accepting 
their identity as culturally Deaf. However, life was made easier through the careful and understanding mentoring of other Deaf peers. Some people described the journey as a natural turn of events, inevitable in a society that has a rigid understanding and acceptance of Deaf people and their culture. Significantly, Maori Deaf participants who were seen to access the Deaf World via all four avenues were commonly referred to in the New Zealand Deaf community (in NZSL) as 'Strong Deaf.' Stating this point - that all Deaf people access the Deaf World in the same way - seems like common sense for those within the Deaf World. It is, however, not apparent to many hearing people, including hearing Maori. In recognition of this, this study aimed to establish clearly that Maori Deaf, as Deaf people, share the universal experience of being Deaf and the local experience of being NZSL users.

\section{A Maori Identity within the Deaf World}

In many ways the term Deaf World assumes that through the use of sign language and shared experiences of being Deaf in a hearing world, Deaf people belong to a 'global community' that is the Deaf World. Carol Padden, an American Deaf researcher, proposed that this 'global community' is comprised of diverse smaller communities that are directly influenced by the wider culture within which they are positioned (Padden 1980). This study found that the New Zealand Deaf community is no exception.

Mainstream values of the hearing Pakeha majority made their way into the New Zealand Deaf community via the residential Deaf schools that were established from 1880 onwards. Although these schools enforced oralist teaching methods that were oppressive (Townshend 1993), Deaf schools were in some ways beneficial for Maori Deaf children in that they exposed them to a critical mass of Deaf children, allowing them to be a part of the covert development of the New Zealand Sign Language (NZSL), Deaf culture, Deaf networks and Deaf organisations. ${ }^{6}$ One of the less understood offshoots of this phenomenon, however, was that until recently (Smith, pers. com. 2004; Ministry of Education 2000) these Pakeha institutions employed historical policies of cultural assimilation - expecting Maori children to behave socially and linguistically as Pakeha and as hearing. These expectations of assimilation were further compounded by physical, social and linguistic isolation from Te Ao Maori and whanau, as 'Patrick', one of the participants of the study, recalled:

When I was five my father wanted me to be involved in a Maori school but there were none around at that time.... So he reluctantly 
sent me to a Deaf school in Auckland. My parents tried to tell me when I went there that I had to behave like a Pakeha while I was there.... You know Deaf school it was a huge contrast! They had a very different culture there. There was the Pakeha hearing as well as oral English speaking culture as well! But hey what could they do - that was the education system was at that time.

The Deaf community's intrinsic link to these institutions has meant that the historical expectation of cultural assimilation that exists in the New Zealand society has had direct repercussions on the culture of the adult Deaf community. Although these social expectations of cultural assimilation are slowly eroding in mainstream hearing society, Deaf people's understanding of the changing public rhetoric is often delayed through barriers to information in public and social spheres. Historically the Deaf community has combated these barriers of access through the creation of a knowledge-sharing and mentoring tradition that exists between older and younger Deaf people. They also have a filtering tradition whereby Deaf people with relative fluency in English, or Te Reo Maori in the case of Maori Deaf, mediate information from the hearing world, such as in media, to those who have limited language fluency in these languages. This study demonstrated that older Maori Deaf mentors did exist in the community and included those who had been mentored themselves by other Maori Deaf and Maori hearing with an understanding of Deaf culture and NZsL. One participant, 'Peter', talked about a noted improvement in knowledge of Te Ao Maori amongst Maori Deaf since 1993. In his experience this improvement in knowledge came through being mentored.

In 1993 lots of Maori Deaf people didn't know what their iwi was they knew nothing. If they learn about their whakapapa it helps them understand what they have to do when they have to give a mihimihi. ['Albert'] taught me about my iwi, well...I already knew who my iwi was but he taught me about my awa [river] and my maunga [mountain]...it helped clarify lots of things! And it's important because if you visit different Marae you need to know about the different iwi so that the kaumatua can make links to your whanau. Like they might say 'oh I know so and so', or something like that.

Although participants spoke positively about maintaining a tradition of knowledge-sharing and mentoring within the community, they also recognised that they were still learning and limited in the information that they could pass on about Te Ao Maori to Maori Deaf rangatahi (youth). 
BEING MAORI DEAF IN A MAORI HEARING WORLD

In this section I discuss what happens to Maori Deaf identity in the context of hearing Maori whanau, and the initiatives Maori Deaf have taken in the Deaf World as a consequence of their experiences in a Maori hearing world.

\section{Being Maori Deaf in the context of hearing whanau}

Relationships with whanau members were determined by the fact that often hearing whanau did not have the experience or understanding of the Deaf World to meet the communication needs of their Deaf child. Although this is relatively common amongst hearing parents of Deaf children (Lane, Hoffmeister and Bahan 1996) it was significant to note how Maori parents who were hearing dealt with this phenomenon.

Historically, the education and medical professions generally promoted oralist methods of communication and learning - lip reading and speaking. The majority of participants of this study grew up during the 'heyday' (1950's - 1970's) of oralism in New Zealand. Their stories described an education and medical system that rejected the use of sign language as a mode of communication and encouraged parents to refrain from using signing in the home. ${ }^{7}$ Participants of this study, however, reported that although their whanau observed this professional advice they also tended to deal with communication barriers by employing more traditional kinaesthetic ways of learning, such as through observing, listening and then doing. 'Me noho puku nga tamaiti' is a phrase used in Te Reo Maori, meaning children should pay attention, observe and listen. It was reported that to some extent this method was successful because of the emphasis placed on observation, and doing - a method that complements Deaf people's preferences for visual methods of learning. However, this study questioned this method of learning and its effectiveness for Maori Deaf participants, principally because the peripheral linguistic information normally available in these settings for Maori hearing children was not available to Deaf children. For example, 'Patricia' recalls:

During my childhood my parents always went to the marae for hui, whanau reunions etc and at the hui they talked about lots of things which I was expected to learn from. [I ask if whanau members interpreted for her.] No...there was no interpreting when I grew up, I had no idea what they were saying. [I ask if she questioned people about what was happening.] I never thought to ask questions, I was 
ignorant and it just never occurred to me to ask questions! I'd just sit there and watch and not know what was happening.

Consequently, although many participants said they were able to 'do Maori things' or 'activities' such as putting down a hangi [earth oven and its contents, where food is cooked in a hole in the ground using heated stones] or participate in kapa haka [traditional songs and dances performed in a group] they often did not know, or were not given the explicit information, about tikanga or whakapapa surrounding the activity. This was compounded by the fact that they found it difficult to develop meaningful relationships with whanau because of communication barriers. Some participants spoke about the development of 'home signs' developed especially between siblings (usually in close proximity of age) and parents who followed the natural instinct to use visual modes of communication. Home signs usually centred on activities in the home such as cooking, eating, gardening and washing. Although these were genuine attempts in communication they were often too crude and brief to maintain meaningful relationships. As a result, most participants were forced to turn to the Deaf community for meaningful communication and relationships.

Maori Deaf initiatives to promote a Maori Deaf turangawaewae [homeground/ a place to stand]

Historically, the New Zealand Deaf community has been stereotyped as a homogenous community - united by Deaf culture, NZSL and Deaf organisations such as Deaf clubs. While these institutions act to unite Deaf people, this study found that Maori Deaf people are becoming increasingly aware of their dual identity as Maori and Deaf. Participants of this study asserted that there was growing interest amongst Maori Deaf to create an environment independent of, yet interconnected with, both Te Ao Maori and the Deaf World.

Participants recognised that part of their identity as Maori was intrinsically linked to whakapapa, and that this knowledge could only be gained from the whanau of the Maori Deaf person. This prompted some to suggest that a partnership needed to be developed between hearing Maori and the Maori Deaf community to remedy this. 'Marie' suggested:

I think Maori Deaf and Maori hearing need to work together. Because really Maori hearing will have the language, knowledge and research, and most of them know where they are from. However Maori Deaf are a little bit limited. Most Maori Deaf will have to 
rely on their whanau because they know the whakapapa. It is the responsibility of the whanau to teach whakapapa. If we had a course to teach these things then, there would have to be an interpreter and also Maori Deaf will have to work with Maori hearing and whanau.

Others were cautious of the role that hearing Maori people, including whanau, would play during this education extension process because of their historical ignorance of the Deaf World and its culture. Maori Deaf leaders such as 'Patrick', spoke of how Maori Deaf people should utilise places such as Ruamoko Marae (a school-based Marae situated at Kelston Deaf Education Centre - KDEC), and how it could play a pivotal role in addressing these issues. 'Patrick' said:

Lots of Maori Deaf have already seen me lecture about the Treaty of Waitangi. I presented a presentation on power point using lots of pictures and visual aids. ...I taught them about what the Treaty is etc.... They were all amazed and wanted to learn more. Some of them want to be like me and stand up and speak, they wanted to talk about things like teaching, etc. The 'marae' [implies Te Komiti o Ruamoko Marae] told them that they could do that and that the 'marae' was open for that type of use. We try to provide a place where we can come together to encourage members of the Maori Deaf community to be in leadership roles and to speak and teach their own people about their own knowledge.

Although not dismissive of the role that hearing Maori could play in addressing the knowledge gap amongst Maori Deaf, most participants felt that being Maori Deaf was a unique identity in itself. They thought that while still connected to the Deaf World and Te Ao Maori, initiatives that try to remedy gaps in knowledge should come from a Maori Deaf perspective.

\section{EXPLORING MAORI DEAF IDENTITIES}

Various international studies have explored the life experiences of ethnic minority groups within Deaf communities, commenting on the effects life experiences have on their socialisation into multiple identities (Ahmad, Darr, Jones and Nisar 1998; Aramburo 1989; Davis and Supalla 1995; Dively 2001). One American study, 'Deaf Persons of Asian American, Hispanic American and African American Backgrounds: A Study of Intraindividual Diversity and Identity' (Foster and Kinuthia 2003:278) developed a model to account for how multiple identities could be conceptualised. 
In Foster and Kinuthia's model each individual had a set of fixed individual primary characteristics such as gender, ethnicity and Deaf identity and secondary characteristics such as age and role beliefs These characteristics were ultimately influenced by: situational conditions - the physical locations in which the individual is socialised; social conditions - the social interactions which determine the resulting affinity and identification with social groups (rejection or exclusion often resulted in dissonance, while inclusion and acceptance resulted in identification with a group); and societal conditions - broad societal trends and patterns such as institutionalised discrimination, mono-culturalism, stereotyping and low socio-economic status.

Unfortunately in the Deaf community where literacy levels are low and where visual modes of communication are much more effective, describing identity development in this way does not sit well. So it was significant that Foster and Kinuthia (2003) took this idea and likened identity to a constellation. In my study I likened this further to a constellation of stars because it is very compatible with both Maori and Deaf cultures. From a Maori perspective, star constellations have traditionally been used for navigational purposes, as markers by which to mark seasons, and as metaphors to depict whakapapa and moral teachings. Using the idea of a star constellation for conceptualising Maori Deaf identity enables Maori Deaf people to connect to Maori metaphors while respecting their innate need for visual ways of expression. Foster and Kinuthia's (2003:285) model suggests:

The resulting proposition is each person is a constellation of many characteristics, some of which are stronger than others but any of which can be drawn out in response to a particular set of conditions, resulting in $[a]$ model of identity that is fluid, responsive, contextual and dynamic. Within this model, identity is a function of the individual's response to a given situation and reflects two or more factors working in isolation or, more often together.

Maori Deaf have many stars/identities that make up the 'constellation', which is the person. This model helps explain how Maori Deaf perceive their identity in different situations, and that identities, as stars, shine forth in response to different contexts. For example, a Maori Deaf person's constellation of stars/ identities may include - parent, Deaf, Maori, sportsperson, worker, male or female, Deaf Club member, kapa haka member, strong Deaf, mainstreamed Deaf, etc. Depending on the situation, star qualities of the appropriate identity shine forth. For example, when Maori Deaf are with other sports people their 
sportsperson identity/star will shine, and when they are with a Deaf friend their Deaf identity/star will shine.

Some Maori Deaf commented that they were often expected, by either hearing Maori or by Deaf, to 'choose' to identify primarily as either Maori or Deaf. Many felt that this was an ignorant expectation. The following examples are excerpts from interviews, in which participants discussed how they were asked to choose a primary identity. Their responses illustrate that Maori Deaf mostly view their identity as more complex and cosmic. 'Jade' had this to say:

'Jack' asked me if I thought I was Maori first of Deaf first? I thought to myself, 'Hey, no that is wrong', why should I have to choose? Why should I have to choose I have a foot in both worlds. You know what I mean you can't split me in half! No that's wrong. When I'm with Deaf people I use sign language and I follow the Deaf-Way, and when I am with Maori I use Te Reo Maori, or with Maori Deaf I sign, that is ok. So you can't make a person choose they all make the person whole. So I have a choice like I can put one foot there, or another foot there, and I am still the same. So I told him [a hearing Maori person] that he is always Maori just like I am always Maori but you can't ask me to choose. That is just not right.

'Patrick' added to this idea and said that in his experience there is pressure for Maori Deaf to choose a primary identity. 'Patrick' stressed that although it is the individual's choice he felt that there was real pressure to conform from groups of hearing Maori and Deaf. He said:

There is an increasing feeling between Maori Deaf that the conflict exists that they have to choose between either Maori or Deaf as their primary identity. Some Maori Deaf people have no confidence in which they are...but they are confident in the Deaf community which makes people think that you identify with being Deaf first and foremost and being Maori comes second. Some Maori Deaf are becoming more confident and they advocate for more Maori involvement within the Deaf community at wananga, etc.... and those people say 'oh I'm Maori first'. That is fine...or if they say they are Deaf first that is fine also because that is their choice. I know that for me it's about balance...like...in a Pakeha environment I behave like a Pakeha and if I'm in a Maori context I behave like a Maori. I know where I am going. You can't say to me that I have to identify 
with one identity either being Maori or Deaf. I think it is a stupid question. The Deaf community needs to be aware of that, as it is really insensitive to the Maori Deaf community. Lots of Maori Deaf feel and identify with being Maori but when they are with Pakeha Deaf they identify primarily with being Deaf - mostly to cover up because they aren't confident enough to say that they are Maori first because the other person is white.... So they put a facade and 'oh yes...I'm Deaf' but then in the Maori community they say 'oh yes I'm Maori first'. They keep quiet, they hold it in. When they gain confidence in themselves they start to value both of their identities. But you cannot make people decide just one identity....

This model of using a constellation of stars as a metaphor for explaining how Maori Deaf perceive their identity was particularly useful for this study. It takes into consideration Maori and Deaf worldviews, acknowledges that identities are shifting and ever changing, and finally, that identities are contextual and responsive. This model is also responsive and consistent with the model describing 'avenues of access to the Deaf community' (Baker and Cokely 1980:56) in that it considers the development of identity as an ongoing and responsive journey.

Forums for the expression of new ideas within the Deaf community are not readily available in New Zealand, and although this paper was presented to an audience at the Deaf View II conference in Auckland in 2004, the audience receiving this paper was largely Pakeha Deaf. In addition, the findings of this research were presented in academic language for a MA thesis. In response to this, the next step is to disseminate the findings of this research into Maori Deaf networks for debate, acceptance and/or revision.

\section{NGA MIHI AROHA}

I would like to say thank you to those people who have supported me while I have been doing this study. I would like to thank my supervisor Rachel McKee and my secondary supervisor David McKee, both of whom have been extremely supportive and fun to work with. I would like to thank Te Komiti o Ruamoko Marae, who has provided tautoko and aroha to me while I have been working on this study. I would also like to say thank you to the Maori Deaf participants who allowed me to interview them. They have been generous in sharing their stories and experiences with me; they are all beautiful people who I feel privileged to know.

Kia Ora. 
NOTES

1 The term Deaf World is borrowed from New Zealand Sign Language sign gloss DEAF WORLD. This sign denotes the concept of the Deaf community, which is characterised by sign language, Deaf culture and Deaf people.

2 Early language initiatives such as Kohanga Reo, established during the early 1980's by Maori communities, aimed to educate Maori pre-schoolers in Te Reo Maori. This initiative later extended to kura kaupapa, or primary school education. In my community, a bilingual unit (Maori and English) was seen as a stepping-stone towards the goal of kura kaupapa and the only kindin my community at the time.

3 One example of such a sign is the old NzsL sign for hangi. The old NZsL sign takes from the form of the sign HANG. When faced with a new word or concept Deaf people tend to develop a sign from visual information on the word or concept. In this instance, some Deaf people used the sign HANG (as hang a person by the neck) to convey hangi. It is likely that this occurred because the word and concept hangi was foreign to Pakeha culture and Deaf people were guessing its meaning through the form of the written word. From a Maori perspective, the head is considered highly tapu or sacred, and so this sign could be seen as highly offensive.

4 Te Komiti o Ruamoko Marae is a group of Maori Deaf community leaders who have aligned a committee with a small school-based marae at Kelston Deaf Education Centre (KDEC) in Auckland. Initially used as an educational marae for students, this marae is becoming increasingly used by Maori Deaf adults for community activities. This increased usage later prompted the development of 'Te Komiti o Ruamoko Marae'. The committee's objectives centre on fostering a Maori Deaf identity for Maori Deaf children and adults and providing them with a place where they can celebrate that identity.

5 The term 'Strong Deaf' is also borrowed from NZsL sign, STrong DEAF. This sign refers to a Deaf person who is a culturally strong Deaf person. This person usually has exceptional sign language skills and is socially active in their Deaf community.

6 Maori participation in the covert development of NZSL is evident in the use of 'Maori signs' or signs that are used specifically for communicating concepts unique to Maori culture, for example the NZSL sign for marae. 
7 Changes over the last ten years such as the introduction of bilingual education (NZSL and written English) within Deaf schools such as Kelston in Auckland, increased sign language interpreters, linguistic recognition of NZSL, and the New Zealand Sign Language Bill being placed before Parliament to make NZSL and official language of New Zealand, have all worked towards increasing the prestige of NZSL as a natural language for Deaf people. Recent medical interventions such as cochlear-implants and the increasing popularity of mainstreaming Deaf children into hearing schools undermines these efforts to preserve Deaf culture and language because they emphasise the need for Deaf people to assimilate into hearing society.

\section{GLOSSARY OF REMAINING MAORI WORDS}

(For readers unfamiliar with Te Reo Maori)

Iwi Tribe

Maori Indigenous people of New Zealand

Marae Traditionally implies the shared courtyard in front of a wharenui (meeting house). In more contemporary times is used to refer to the whole meeting area, including the wharenui (meeting house) and its surrounding structures.

Pakeha A person of predominantly European descent

Te Reo Maori Maori Language

Tikanga Protocol

Whakapapa Genealogy or history

Whanau Family - includes extended family

\section{REFERENCES}

Ahmad, W., Darr, A., Jones, L. and Nisar, G. 1998 Deafness and Ethnicity: Services, Policy and Politics, Bristol: The Policy Press.

Aramburo, A.J. 1989 'Sociolinguistic Aspects of the Black Deaf Community', in C. Lucas (ed) The Sociolinguistics of the Deaf Community, New York: Academic Press: 103-119.

Baker, C. and Cokely, D. 1980 American Sign Language: A Teacher's Resource Text on Grammar and Culture, Silver Spring, MD: TJ Publishers.

Baker-Shenk, C. and Kyle, J.G. 1990 'Research with Deaf People: Issues and Conflicts', Disability, Handicap and Society, 5(1): 65-75. 
Davis, J. and Supalla, S. 1995 'A Socioloinguistic Description of Sign Language Use in a Navajo Family', in C. Lucas (ed) Sociolinguistics in Deaf Communities, Washington D.C: Gallaudet University Press: 77-106.

Dively, V.L. 2001 'Contemporary Native Deaf Experience: Overdue Smoke Rising', in L. Bragg (ed) Deaf World: A Historical Reader and Primary Sourcebook, New York: New York University Press: 390-405.

Foster, S. and Kinuthia, W. 2003 'Deaf Persons of Asian American, Hispanic American, and African American Backgrounds: A Study of Intraindividual Diversity and Identity' Journal of Deaf Studies and Deaf Education 8(3):271290.

Ladd, P. 2003 Understanding Deaf Culture: In Search of Deafhood, Clevedon: Multilingual Matters Ltd.

Lane, H., Hoffmeister, R. and Bahan, B. 1996 A Journey into the DEAF-WORLD, San Diego: Dawnsign Press.

Ministry of Education, Transition Working Group 2000 National Plan for the Education of Deaf and Hearing Impaired Learners in Aotearoa/New Zealand: For Early Childhood and School Sector Learning, Wellington: Ministry of Education, Special Education Services.

Padden, C. 1980 'The Deaf Community and the Culture of Deaf People', in C. Baker and R. Batterson (eds) Sign Language and the Deaf Community: Essays in Honour of William. C. Stokoe, USA: National Association of the Deaf: 89-103.

Smith, E. 2004 Personal communication with Kirsten Smiler, Wellington. Townshend, S. 1993 'The Hands Just have to Move': Deaf Education in New Zealand - A Perspective from the Deaf Community, Unpublished Masters Thesis, Massey University.

Smith, L. T. 1999 Decolonising Methodologies: Research and Indigenous Peoples, Dunedin: Otago University Press. 